\title{
Sexual and reproductive health needs of adolescent girls from conservative and low-income families in Erzurum, Turkey
}

\author{
Nesrin Reis ${ }^{1}$, Dilek Kilic ${ }^{2}$, Raziye Engin ${ }^{2}$, Ozlem Karabulutlu ${ }^{2}$ \\ ${ }^{1}$ Bezmialem University, Health Sciences Faculty, Department of Nursing, Istanbul, Turkey; \\ ${ }^{2}$ Ataturk University, Health Sciences Faculty, Department of Nursing, Erzurum, Turkey; *Corresponding Author: dilekk@atauni.edu.tr
}

Received 3 February 2011; revised 28 April 2011; accepted 5 May 2011.

\begin{abstract}
The objective of this survey was to determine the sexual and reproductive health needs of conservative and/or economically challenged adolescent girls. A total of 310 subjects (16.5 \pm 2.2 years old), attending three private institutes teaching Islamic matter and the holy Quran and two private institutes teaching carpet-weaving in Erzurum, Turkey, were interviewed between November 2004 and February 2005. The questionnaire covered knowledge on reproductive health and sexual matters to attain their feelings prior to their first menarche, their practices during menstruation, and their awareness of gynecological and sexually transmitted diseases as well as their attitudes toward and responsiveness to domestic violence. Their responses showed that these issues were considered taboo and/or embarrassing to share. Also, a considerable percentage of the girls had no or limited knowledge on reproductive health and sexual matters and mismanaged gynecological problems and domestic violence. Moreover, those had knowledge revealed that their sources were non-scientific information from unprofessional individuals. In conclusion, the conservative and/or economically challenged adolescent girls who are not attending regular high schools need professional lectures on reproductive health and sexual matters.
\end{abstract}

Keywords: Reproductive Health; Sexual Health; Adolescent Girls

\section{INTRODUCTION}

Of the world population in 2000, over one billion people were adolescents (10 - 19 years old) and 85\% of them lived in developing countries, mainly Asian countries [1]. They will contribute to population growth in next decades, suggesting that their education on sexual and reproductive health and their needs are extremely critical [2]. Moreover, they may be vulnerable to several diseases and problems, such as HIV and sexually transmitted diseases (STD) as well as experiencing unintended pregnancies and maternal complications, if they receive inaccurate or incomplete information on reproductive health. A survey conducted by Polish researchers ascertained that adolescent girls were sexually active and $41.1 \%$ of them were referred to ineffective methods, which led to withdrawal during sexual intercourse, resulting in a higher rate of unwanted pregnancy, STD, and other sexual and reproductive health problems [3]. In fact, it was reported that $70 \%$ of the people STDs were at age ranging from 15 to 24 years [4]. Adolescent sexual and reproductive health education is still a neglected issue in many countries [5]. Especially the adolescents from the rural part of the developing countries are disadvantageous due to unavailability and/or inadequacy of reproductive health care services and trainings [6-10]. While the reproductive and sexual health of adolescents is acknowledged as good from developed countries to Western Europe countries [11,12], there are studies reporting that the reproductive and sexual health of adolescents in some European countries [13,14], Canada [12,15], and America [15-17] are poor. Worldwide, societal shifts and behavioural patterns exacerbated by unique developmental vulnerabilities create a confluence of factors that place today's adolescents at heightened risks for poor health outcomes [16]. Therefore, Worldwide, all adolescents need sexual and reproductive health education and legal acts $[13,16]$. International Conference on Population and Development held in Cairo in 1994 recognized the reproductive rights as fundamental human rights [9]. These rights cover that all adolescents should receive health care services and that 
they should be given a high-quality sexual and reproductive health education. However, before provision of such service, field surveys must be performed to determine knowledge on and attitudes toward reproductive health and sexual matters, which may vary the culture, religion, economical and educational statues, and environmental factors. Therefore, in this preliminary study, we conducted a survey involving adolescent girls from conservative and/or economically challenged families to determine their knowledge on and attitudes toward reproductive health and sexual matters and explore their needs.

\section{METHODS}

\subsection{Participants and Their Characteristics}

This descriptive study included 220 adolescent girls attending three private institutes teaching the Quran as well as some Islamic issues and 90 adolescent girls attending two private institutes teaching carpet-weaving in Erzurum, Turkey. The subjects voluntarily participated in this study from November 2004 to February 2005.

The majority adolescent girls attending these courses had completed current the 8-year compulsory education (elementary and intermediate school) imposed by law of the state ( $\mathrm{n}=151,82.9 \%$ ). Some of them had only an earlier the 5-year mandatory elementary school education ( $\mathrm{n}=106,34.2 \%)$. However, there also 16 subjects who had no education (Table 1). Institutes teaching the Quran and religious rheoretics were boarding institutes where education, food, and shelter are provided. The girls attending these courses were mostly from families with low-income and/or had many children. Because both kinds of institutes are regulated by the government, families intend to take advantage of learning and practicing Islam in a proper environment and of making living with their skills.

The mean age was $16.5 \pm 2.2$ years. All of them were single and $82.9 \%$ of them had compulsory elementary education. Majority were urban residents (78.7\%) and economically dependents (67.4\%). Almost half the subjects relied on the state social security system (SSS) due to their parent's employment in the government (37.7\%) and insurance system due to their parents' private small businesses (17.8\%). The majority of the other half was supported by the government (33.5\%) (Table 1).

\subsection{Ethics}

Written permission was taken from the related institutions before the research. The aim of the research was explained to the adolescent girls, and they were informed that if they prefer not to continue, they could withdraw from the study any time they wish. Furthermore, they were informed that their decision to participate into the research would not affect their attendance to the course. They were assured that their names and the names of their institutions were confidential and they were free to respond to whichever question(s) they wanted.

Table 1. Socio-demographic characteristics of the adolescent girls.

\begin{tabular}{lcc}
\hline & $\mathrm{N}$ & $\%$ \\
\hline Educational status & 27 & 8.7 \\
Illiterate & 16 & 5.2 \\
Literate & 106 & 34.2 \\
Elementary school (5 years) & 151 & 48.7 \\
Intermediary school (3 years) & 10 & 3.2 \\
$\quad$ High school (3 - 4 years) and university (2 - 6 years) & & 61.0 \\
Birth place & 189 & 39.0 \\
$\quad$ Urban & 121 & 78.7 \\
Rural & & 21.3 \\
Current address & 244 & 67.4 \\
City centre & 66 & 27.4 \\
Suburb & & 5.2 \\
Income status & 209 & 37.7 \\
Lower than outcome & 85 & 17.8 \\
Equal to outcome & 16 & 33.5 \\
Higher than outcome & & 11.0 \\
Health insurance & 117 & 55 \\
SSS & 104 & 34 \\
Individual membership to the state insurance system & & \\
Green card & & \\
No health insurance & & \\
\hline
\end{tabular}




\subsection{Procedure and Data Collection}

Prior to the research, the researchers visited the institutes to evaluate facilities for pre-interviews with the adolescent girls about the nature of the study. In this meeting, the researchers focused upon sexuality, to a large extent, the first menarche/pubertal changes, gynecologic diseases, familial violence such as restrictions/prohibitions and verbal abuse.

The relevant literature was reviewed for the establishment of semi-structured questionnaire. The data were collected with face-to-face interviews and included demographic characteristics and sexual and reproductive health needs of the adolescent girls. Each interview lasted approximately 30 - 40 minutes.

\subsection{Data Analysis}

The PROC MEANS and UNIVARIATE procedures were employed to determine descriptive statistics of demographic characteristics and sexual and reproductive health needs (SPSS, Version 10.0, Chicago, IL, USA). Mean, standard deviation, range and frequency of response variables were reported.

\section{RESULTS}

\subsection{Knowledge and Management of Menarche and Menstruation}

One-third of the subjects had no knowledge prior to their first menarche (Table 2). Half of the subjects who had knowledge about menarche $(n=209)$ received information from their family members, whereas only received information from health professionals ( $n=20,9$, 6). Moreover, majority of these girls had no knowledge on menstruation physiology (79.7\%). Feeling after experiencing the first menarche was mix; $43 \%$ of the subjects had uncomfortable feelings, such as anxiousness, nervousness, and feeling dirty; $20 \%$ of them were happy about considering them blooming; and 35.5\% of them had both feelings. Menstruation management practices were hot application (38.7\%), taking painkiller (16.1\%), and having more frequent bath $(11.9 \%)$. While one-fifth of the subjects practiced all these, almost other one-fifth did not take any action to cope with menstruation.

\subsection{Knowledge on Reproductive Health}

Dysmenorrhea (23.9\%) and irregular menses (18.1\%) were two most common gynecologic problems that study subjects experienced (Table 3). Only one subject $(0.3 \%)$ had not experience their first menarche at time of survey. More than one-third of the girls did not prefer to share their gynecologic health status. Overall, 62.9\% of the girls acknowledged presence of gynecologic problems. However, majority of the adolescent girls (87.4\%) reported that they did not consider health unit for solution (87.4\%) and preferred female doctor if they would have to visit health unit (91.3\%).

Table 2. Knowledge and management of menarche and menstruation of the adolescent girls.

\begin{tabular}{|c|c|c|}
\hline & $\mathrm{N}$ & $\%$ \\
\hline \multicolumn{3}{|l|}{ Getting information before the first menarche } \\
\hline Yes & 209 & 67.4 \\
\hline No & 101 & 32.6 \\
\hline \multicolumn{3}{|l|}{ The source of information } \\
\hline Friend & 39 & 18.7 \\
\hline Mother & 58 & 27.7 \\
\hline Sister & 41 & 19.6 \\
\hline Health staff & 20 & 9.6 \\
\hline Other (book, media, etc.) & 15 & 7.2 \\
\hline Multiple (friend, sister and media) & 36 & 17.2 \\
\hline \multicolumn{3}{|l|}{ Knowledge on menstruation } \\
\hline Yes & 63 & 20.3 \\
\hline Not knowing & 247 & 79.7 \\
\hline \multicolumn{3}{|l|}{ Feelings at the first menarche } \\
\hline Unfavorable feelings (anxiousness, nervousness, fear, dirtiness, etc.) & 136 & 43.9 \\
\hline Favorable feelings (to be on the verge of becoming a young girl, etc.) & 64 & 20.6 \\
\hline Mix feeling & 110 & 35.5 \\
\hline \multicolumn{3}{|l|}{ Menstruation management } \\
\hline Showering & 37 & 11.9 \\
\hline Taking painkillers & 50 & 16.1 \\
\hline Hot application & 120 & 38.7 \\
\hline Others (more than one application) & 61 & 19.7 \\
\hline No action & 42 & 13.6 \\
\hline
\end{tabular}


Table 3. Gynecologic health needs of the adolescent girls.

\begin{tabular}{lcc}
\hline & $\mathrm{N}$ & $\%$ \\
\hline Gynecologic problems & & 18.1 \\
Irregularity of menses & 56 & 23.9 \\
Dysmenorrhea & 74 & 3.2 \\
Over bleeding & 10 & 0.3 \\
No menses & 1 & 5.5 \\
Genital infections & 17 & 11.9 \\
Two or more problems & 37 & 37.1 \\
No response & 115 & 12.6 \\
Reference to a health unit for the problems & 39 & 87.4 \\
Yes & 271 & 91.3 \\
No & & 283 \\
Preference of doctor's gender & 2 & 0.6 \\
Female & 25 & 8.1 \\
Male & & \\
Either & & 2 \\
\hline
\end{tabular}

Almost half of the subject had no knowledge on sexuality and almost another half did not want to share their knowledge on sexuality (Table 4). Information source was highly variable; being elder sister and/or close friend the major source. Likewise, more than half of the subjects were not willing to share their information source $(55.1 \%)$ preferred to keep silent and did not answer the question, whereas the other half $(18.7 \%$, $14.5 \%)$. Frequency of subjects that were aware of sexually transmitted diseases (STD) was similar to frequency of the subjects who had general knowledge on sexual matters. Only $13.2 \%$ of the subjects had knowledge on STD's and almost half of them did not want to talk about this issue. More than half of the subjects were not willing to express their opinion on birth control (52.6\%). Other half had knowledge on contraceptive methods. One percent of the subjects were aware of traditional methods such as coitus interruptus and vaginal douching.

\subsection{Experience of and Attitude toward Domestic Violence}

Three quarters of the subjects did not want to talk about familial violence (Table 5). Others were witness to verbal abuse (12.9\%), social abuse $(9.4 \%)$, physical assault (2.9\%), and sexual violence (1.0\%) between their parents. Half of the subjects did not prefer to express their feeling about domestic violence. Those expressed their feeling were approval (6.1\%), disapproval (hatred, fear, fury) (24.2\%), and ignorance (20.0\%). Interestingly, none of the subjects shared domestic violence with health or security personnel and $15.1 \%$ of them did not share it with anybody. Other family members (17.4\%) and friends (12.6\%) were the primary contacts to mention domestic violence. Again, more than half of the subjects did not want to answer who was the person to share domestic violence.

\section{DISCUSSION}

The Turkish education system is secular and "health science" is a mandatory in high school curriculum. However, conservative and low-income family or families living in rural may prefer especially their daughters to continue on their education in some institutes offering religious program or skills. We assumed that these groups of adolescent girls might need more assistance to improve their knowledge and awareness on reproductive health and sexual matters because their current curriculum does not cover these issues. Table 1 indicated that our study group was not only conservative but also were educationally deficient and from low-income families. The majority were either hesitant to talk about their first menarche experience and menstruation cycle or not informed at all/improperly informed before the first menarche and during menstruation and did not know how to manage their menstruation cycle. Instead of perceiving these as a result of a health physical and physiological development, they were swamped with depression signs (Table 2). Similar information source and feelings at pubertal age by the girls were also reported in other surveys conducted in India [18] and Pakistan [6]. These suggest that such education should be emphasized in schooling adolescents effectively by teachers and compensated in nonschooling adolescents through regular workshops by local health care providers.

Despite presence of gynecological discomforts and needs for professional assistance, our study subjects were not willing to consult health unit. In case they wanted to visit a doctor, female doctor was preferred 
(Table 3). This could be due to considering clinics disturbing and non-confidential [6], unavailability of such service [19], not knowing to get help from health cabinets [8]. Young people need access to quality clinical services that offer effective treatments and vaccines as well as proper sexual education. Mbonye reported that the adolescents with gynecological problems were free of these problems and learned how to manage these problems upon consulting health units in Uganda [20]. These findings emphasize the necessity of the youth development programs covering health education and care to economically challenged adolescents.

The half of our study subjects was not willing to share their knowledge, knowledge source on sexual matters and STD as well as birth control methods. The other half were either not knowledgeable or had limited knowledge (Table 4). Naturally, it is the duty of families to give information to adolescents on sexuality, STD's and contraception, but families of our study group perhaps did not know or were not aware of these issues. Surprisingly, other studies also show that children/adolescents rarely receive information on their sexual matters from their parents [21,22], which may be account for performing risky behavior due to possible variation of accuracy in knowledge from various sources [23]. Girls with a longer period of training were shown to conduct less risky sexual behavior than those with a shorter period of training [24]. In another study, it was shown that Nigerian girls lacking sexual education at school and home tended to perform malicious sexual behaviors such as involuntary pregnancy and injuries and infections in genital system [10]. In Turkey, pre-marriage sex is not acceptable adolescent girls. Upon marriage, some relatives or honored friends inform the couple about sexual matters including pregnancy and birth control. In case of extra-marital pregnancy, criminal act of honor killings or committing suicide may be encountered, especially in communities where feudalism is still exits. Such perception, sometimes may lead improper places or methods to abort in case of unauthorized marriages. In Kenya and Zambia [7], it was reported that referred unmarried pregnant girls to abortion. De Jong et al (2005) have shown that in Arabic and Iranian communities, it is a taboo to discuss sexuality and the young are unable to receive knowledge concerning these subjects at a satisfying and adequate level. Overall, these studies suggest that cultural and religious factors, inadequate information, limited usage of services of reproductive health usually appear to make the adolescent girls prone to some diseases including STD's and HIV-AIDS and socially unacceptable cases including unwanted and unplanned pregnancy, personal sexual and reproductive health problems [20,26]. Disadvantaged groups exists among adolescents in terms of sexual and reproductive health despite presence of the sexual and reproductive health services and training programmes directed at adolescents in developed countries $[11,12,16]$. It is reported that the age of their first sexual experience, the

Table 4. Reproductive health needs of the adolescent girls.

\begin{tabular}{|c|c|c|}
\hline & $\mathrm{N}$ & $\%$ \\
\hline \multicolumn{3}{|l|}{ Knowledge on sexual matters } \\
\hline Yes & 41 & 13.2 \\
\hline No & 138 & 44.5 \\
\hline No response & 131 & 42.3 \\
\hline \multicolumn{3}{|l|}{ Information on sexual matters } \\
\hline Elder sister/Female friend & 58 & 18.7 \\
\hline Various books & 45 & 14.5 \\
\hline Magazine and journals & 9 & 2.9 \\
\hline Television & 21 & 6.8 \\
\hline Multiple communication resources (Friends, journals, TV, etc.) & 6 & 2.0 \\
\hline No response & 171 & 55.1 \\
\hline \multicolumn{3}{|l|}{ Knowledge on sexually transmitted diseases } \\
\hline Yes & 41 & 13.2 \\
\hline No & 138 & 44.5 \\
\hline No response & 131 & 42.3 \\
\hline \multicolumn{3}{|l|}{ Awareness of contraceptive methods } \\
\hline At least 1 effective method & 72 & 23.2 \\
\hline Two or more effective methods & 72 & 23.2 \\
\hline Traditional methods & 3 & 1.0 \\
\hline No response & 163 & 52.6 \\
\hline
\end{tabular}


Table 5. Experience of and attitude toward domestic violence of the adolescent girls.

\begin{tabular}{lcc}
\hline & $\mathrm{N}$ & $\%$ \\
\hline Types of familial violence & & 12.9 \\
$\quad$ Verbal violence & 40 & 2.9 \\
Physical violence & 9 & 9.4 \\
Imposition of restrictions & 29 & 1.0 \\
Sexual violence & 3 & 73.8 \\
No response & 229 & 6.1 \\
Feelings towards the one who conducts violence & & 12.6 \\
Love & 19 & 3.5 \\
Hatred & 39 & 8.1 \\
Fear & 11 & 20.0 \\
Fury & 25 & 49.7 \\
Nothing & 62 & 12.6 \\
No response & 154 & 17.4 \\
Person choice to talk about violence & & 1.0 \\
Family member & 39 & 00.0 \\
Friend & 54 & 15.1 \\
Relative & 3 & 53.9 \\
Professional (health and/or security) & 0 & \\
Nobody & 47 & 167 \\
No response & & \\
\hline
\end{tabular}

pregnancy rate, the use of contraception, HIV knowledge, and STI rate from one population to another in these groups, as well as adolescents portray high risk reproductive health behaviour [11,12]. Therefore, it is imperative to provide optimal sexual and reproductive health education. It is recommended to apply a peer-based approach in reproductive health and sex education to the adolescents $[17,27,28]$. Strategies should consider developmental needs of age of the adolescents and their social context $[29,30]$.

Our study population did not want to share domestic violence and majority did not notify this to authorities in case it happened (Table 5). Domestic violence can adversely affect adolescents' attitudes on sexual matters and mental and behavioral health as well as destroys the development of self-concept and body image [31-34]. Information and counseling service should be provided to parents especially when their girls become adolescent, to facilitate establishment for their happy and health marriages in future.

In conclusion, our survey revealed that conservative and/or economically challenged adolescent girls with up to intermediate education were in need of accurate and professional education on sexuality and reproductive health. However, at this point, we were unable to indicate what characteristics of these adolescents (religion, low education, or low-income) could be attributed to their responses. Teachers and health professionals should be facilitated by authorities to provide proper reproduc- tive health and sex education to adolescents attending institutes whose curriculum does not cover this topic. Cross-cultural studies involving adolescents from different economic and education background should be performed to determine factors underlying different attitudes toward sexuality.

\section{REFERENCES}

[1] Gubhaju, B.B. (2002) Adolescent reproductive health in Asia. IUSSP Regional Population Conference, "SouthEast Asia's Population in a Changing Asian Context”. Bangkok, Thailand.10-13 June 2002.

[2] Rani, M. and Lule, E. (2004) Exploring the socioeconomic dimension of adolescent reproductive health: A multicountry analysis. International Family Planning Perspectives, 30, 110-117. doi:10.1363/3011004

[3] Woynarowska, B., Malkowska, A. and Tabak, I. (2006) Sexual behaviour among adolescents aged 16 - 18 years in Poland in 2005. Ginekologia Polska, 77, 667-677.

[4] Miles, K., Shaw, M., Paine, K., Hart, G.J. and Ceesay, S. (2001) Sexual health seeking behaviours of young people in the Gambia. Journal of Adolescence, 24, 753-764. doi:10.1006/jado.2001.0442

[5] The World Bank. (2010) The World Bank’s Reproductive Health Action Plan 2010-2015. http://reliefweb.int/node/ 25364

[6] Ali, M., Bhatti, M.A. and Ushijima, H. (2004) Reproductive health needs of adolescent males in rural Pakistan: An exploratory study. The Tohoku Journal of Experimental Medicine, 204, 17-25. 
doi:10.1620/tjem.204.17

[7] Warenius, L.U., Faxelid, E.A., Chishimba, P.N., Musandu, J.O., Ong'any, A.A. and Nissen E.B.M. (2006) Nurse-Midwives' attitudes towards adolescent sexual and reproductive health needs in Kenya and Zambia. Reproductive Health Matters, 14, 119-128. doi:10.1016/S0968-8080(06)27242-2

[8] Omar, H. (2006) Reproductive care for adolescents with disability: where should they get it? Journal of Pediatric and Adolescent Gynecology, 19, 109-115.

doi:10.1016/j.jpag.2006.01.007

[9] Bearinger, L.H., Sieving, R.E., Ferguson, J. and Sharma, V. (2007) Global perspectives on the sexual and reproductive health of adolescents: patterns, prevention, and potential. Lancet, 369, 1220-1231. doi:10.1016/S0140-6736(07)60367-5

[10] Etuk, S.J., Ihejiamaizu, E.C. and Etuk, I.S. (2004) Female adolescent sexual behaviour in Calabar, Nigeria. The Nigerian Postgraduate Medical Journal, 11, 269273.

[11] Avery, L. and Lazdane, G. (2010) What do we know about sexual and reproductive health of adolescents in Europe. European Journal of Contraception and Reproductive Health Care, 15, 54-66. doi:10.3109/13625187.2010.533007

[12] Eleanor, M.T. (2008) Sexuality and sexual health of Canadian adolescents: Yesterday, today and tomorrow. The Canadian Journal of Human Sexuality, 17, 85-95.

[13] Fronteira, I., Oliveira da Silva, M., Unzeitig, V., Karro, H. and Temmerman, M. (2009) Sexual and reproductive health of adolescents in Belgium, the Czech Republic, Estonia and Portugal. European Journal of Contraception and Reproductive Health Care, 14, 215-220. doi:10.1080/13625180902894524

[14] Rademakers, J., Mouthaan, I., de Neef, M. (2005) Diversity in sexual health: Problems and dilemmas. The European Journal of Contraception \& Reproductive Health Care, 10, 207-211. doi:10.1080/13625180500279847

[15] Singh, S., Darroch, J.E., Frost, J.J. (2001) Socioeconomic disadvantage and adolescent women's sexual and reproductive behavior: The case of five developed countries. Perspectives on Sexual and Reproductive Health, 33, 251-258.

[16] Bearinger, L.H., Sieving, R.E., Ferguson, J. and Sharma, V. (2007) Global perspectives on the sexual and reproductive health of adolescents: patterns, prevention and potential. The Lancet, 369, 1220-1231. doi:10.1016/S0140-6736(07)60367-5

[17] Roswith, R. (2003) Sexual and reproductive life of women: Gender equality in women's reproductive health in Western Europe and the US. Cross Cultural Issues in Women's Health, 45, 123-143.

[18] Kumar, R., Raizada, A., Aggarwal, A.K. and Kaur, M. (2000) Adolescent behaviour regarding reproductive health. Indian Journal of Pediatrics, 67, 877-882. doi:10.1007/BF02723949

[19] Katz, K. and Nare, C. (2002) Reproductive health knowledge and use of services among young adults in Dakar, Senegal. Journal of Biosocial Science, 34, 215-231. doi:10.1017/S0021932002002158

[20] Mbonye, A.K. (2003) Disease and health seeking pat- terns among adolescents in Uganda. International Journal of Adolescent Medicine and Health, 15, 105-112. doi:10.1515/IJAMH.2003.15.2.105

[21] Adjahoto, E.O., Hodonou, K.A., de Souza, A.D., Tete, V.K. and Baete, S. (2000) Teenage knowledge about sex. Sante, 10, 195-199.

[22] Kapamadzija, A., Bjelica, A. and Segedi, D. (2000) Sex knowledge and behavior in Male high school students. Medicinski Pregled, 53, 595-599.

[23] Zhang, L., Gao, X., Dong, Z., Tan, Y. and Wu, Z. (2002) Premarital sexual activities among students in a university in Beijing, China. Sexually Transmitted Diseases, 29, 212-215. doi:10.1097/00007435-200204000-00005

[24] Leite-Ida, C., Rodrigues-Rdo, N. and Fonseca-Mdo, C. (2004) Factors associated with sexual and reproductive behavior among adolescents from the Northeast and Southeast regions of Brazil. Cadernos de Saúde Pública, 20, 474-81.

[25] De Jong, J., Jawad, R., Mortagy, I. and, Shepard, B. (2005) The sexual and reproductive health of young people in the Arab countries and Iran. Reproductive Health Matters, 13, 49-59. doi:10.1016/S0968-8080(05)25181-9

[26] Franzini, L., Marks, E., Cromwell, P.F., Risser, J., McGill, L., Markham, C., Selwyn, B. and Shapiro, C. (2004) Projected economic costs due to health consequences of teenagers' loss of confidentiality in obtaining reproductive health care services in Texas. Archives of Pediatrics \& Adolescent Medicine, 158, 1140-1146. doi:10.1001/archpedi.158.12.1140

[27] Hobcraft, G. and Baker, T. (2006) Special needs of adolescent and young women in accessing reproductive health: Promoting partnerships between young people and health care providers. International Journal of Gynecology and Obstetrics, 94, 350-356. doi:10.1016/j.ijgo.2006.04.024

[28] Valvano, T.J. (2009) Legal issues in sexual and reproductive health care for adolescents. Clinical Pediatric Emergency Medicine, 10, 60-65. doi:10.1016/j.cpem.2009.01.004

[29] Brieger, W.R., Delano, G.E., Lane, C.G., Oladepo, O. and Oyediran, K.A. (2001) West African Youth Initiative: Outcome of a reproductive health education program. Journal of Adolescent Health, 29, 436-446. doi:10.1016/S1054-139X(01)00264-6

[30] Magnani, R.J., Karim, A.M., Weiss, LA., Bond, K.C., Lemba, M. and Morgan, G.T. (2002) Reproductive health risk and protective factors among young in Lusaka, Zambia. The Journal of Adolescent Health, 30, 76-86. doi:10.1016/S1054-139X(01)00328-7

[31] Ackard, D.M. and Neumark-Sztainer, D. (2002) Date violence and date rape among adolescents: Associations with disordered eating behaviors and psychological health. Child Abuse \& Neglect, 26, 455-473. doi:10.1016/S0145-2134(02)00322-8

[32] Ackard, D.M., Neumark-Sztainer, D. and Hannan, P. (2003) Dating violence among a nationally representative sample of adolescent girls and boys: associations with behavioral and mental health. The Journal of Gender Specific Medicine, 6, 39-48.

[33] Ackard, D.M., Eisenberg, M.E. and Neumark-Sztainer, D. 
(2007) Long-term impact of adolescent dating violence on the behavioral and psychological health of male and female youth. The Journal of Pediatrics, 151, 476-481. doi:10.1016/j.jpeds.2007.04.034

[34] Silverman, J.G., Raj, A., Mucci, L.A. and Hathaway, J.E.
(2001) Dating violence against adolescent girls and associated substance use, unhealthy weight control, sexual risk behavior, pregnancy, and suicidality. The Journal of American Medical Association, 286, 572-579. doi:10.1001/jama.286.5.572 